\title{
Global impacts of the Atlantic Multidecadal Variability during the boreal winter
}

doi: $10.22498 /$ pages.25.1.7

\author{
Yohan Ruprich-Robert ${ }^{1}$, Rym Msadek ${ }^{2}$ \\ 1 Atmosphere and Ocean Sciences, Princeton University, and NOAA/GFDL, Princeton, New Jersey \\ 2 CNRS-CERFACS, Toulouse, France
}

\section{Introduction}

During the last century, the observed annual mean North Atlantic sea surface temperatures (SSTs) exhibited multidecadal fluctuations superimposed onto a longterm warming trend. This multidecadal variability has been referred to as the Atlantic Multidecadal Oscillation (AMO) or Variability (AMV). The SST anomalies that define the AMV are characterized by a basin-scale anomalous pattern that has the same sign in the whole North Atlantic, and a maximum loading in the subpolar gyre (SPG) region (Fig. 1).

Previous studies have shown that the AMV is associated with, and possibly the source of, marked climate anomalies over many areas of the globe. This includes droughts over Africa and North America (Mohino et al., 2011; Enfield et al., 2001), decline in Arctic sea ice (Mahajan et al., 2011), changes in Atlantic tropical cyclone activity (Vimont and Kossin, 2007), and recently it has been linked with the global temperature hiatus (McGregor et al., 2014; Li et al., 2015). Additionally, due to its upstream location, the North Atlantic SST is a main actor of the European climate variability. Sutton and Hodson (2005) and Sutton and Dong (2012) argue for the existence of a causal link between the warm phase of the AMV and warmer conditions than normal over Central Europe, drier conditions over the Mediterranean basin, and wetter conditions over Northern Europe during boreal summer. A number of studies suggest also that the AMV could impact the winter North Atlantic - Europe atmospheric circulation by modulating the number of blocking events and/or by driving North Atlantic Oscillation-like anomalies (Hakkinen et al., 2011; Davini et al., 2015; Peings and Magnusdottir, 2014, 2015; Omrani et al., 2014; Gastineau and Frankignoul, 2015). Furthermore, the AMV and its Pacific counterpart, the Interdecadal Pacific Oscillation (IPO), have been linked to multidecadal changes in the frequency of North American droughts (McCabe et al., 2004; Chylek et al., 2014). However, whether the concomitant forcing of the Atlantic and Pacific arise from a coincidence or reveal a causal link between Atlantic and Pacific decadal anomalies remains uncertain.

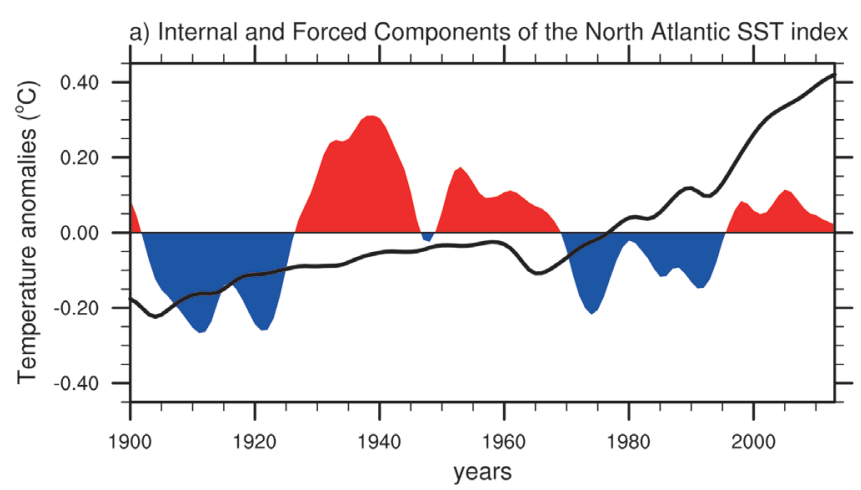

b) AMV spatial pattern

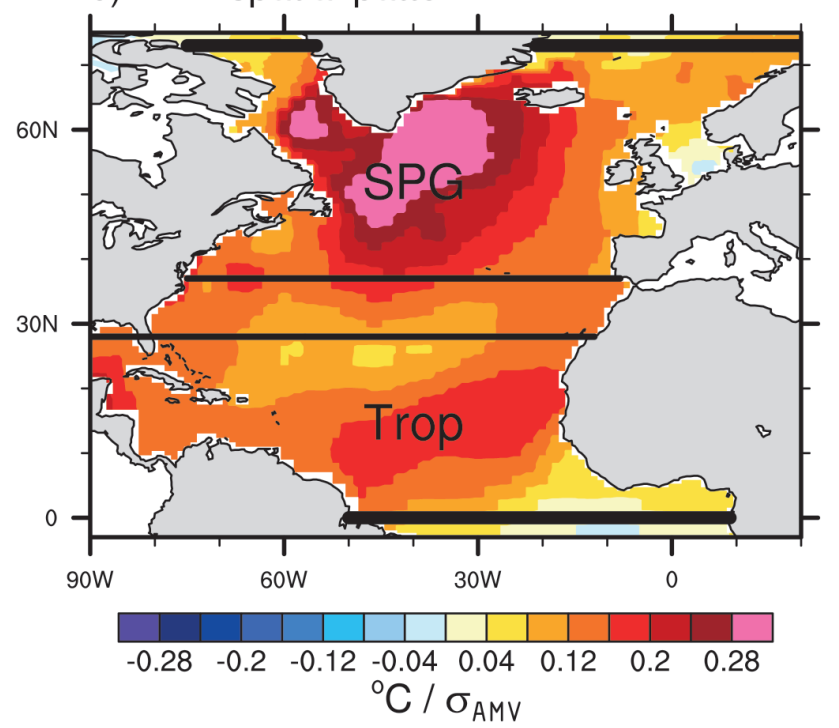

Figure 1: (a) Internal (red and blue) versus external (black) components of the observed North Atlantic SST multidecadal variability following Ting et al. (2009) definition. (b) Regression map of the observed annual mean SST (ERSSTV3; Smith et al. 2008) on the internal component of the North Atlantic SST index (i.e., the AMV index); units are ${ }^{\circ} \mathrm{C}$ per standard deviation of AMV index. Both SST field and AMV index time series have been low pass filtered prior to computing the regression, using a Lanczos filter (21 weights with a 10-yr cutoff period). The black latitudinal lines in b show the subpolar and tropical domains used for the SPG_AMV and Trop_AMV experiments (see section 2b). Figure from Ruprich-Robert et al. (2017). (C)American Meteorological Society. Used with permission. 
Given the many potential climate impacts of the AMV at decadal timescales, it is crucial to improve our knowledge of the mechanisms associated with AMV teleconnections. A better understanding of these mechanisms could help advance the prediction of AMV impacts and hence decadal climate predictions. We are providing here a short description of a recent coordinated multi-models study that investigates the global impacts of the observed $\mathrm{AMV}$, in which the respective role of the extratropical and tropical parts of the AMV have been identified.

\section{Description of model experiments}

To evaluate the AMV climate impacts, we performed idealized experiments using state-of-the art global coupled climate models, in which the North Atlantic SSTs are restored to time-invariant anomalies corresponding to an estimate of the internally driven component of the observed AMV (following Ting et al. 2009's approach; Fig. 1). The three models used in this study are the GFDLCM2.1 (Delworth et al., 2006; Wittenberg et al., 2006), the NCAR CESM1-CAM5 (hereafter CESM1; Kay et al., 2015), and the GFDL-FLOR (Vecchi et al., 2014). All three models use a nominal $1^{\circ}$ horizontal ocean resolution but employ different atmospheric resolutions. Specifically, the atmospheric resolution is about $2^{\circ}$ in CM2.1, $1^{\circ}$ in CESM1, and $0.5^{\circ}$ in FLOR.

Two experiments were performed with the three models, namely Full_AMV+ and Full_AMV-, in which SST anomalies corresponding to +1 or -1 standard deviation of the AMV index (i.e., plus or minus the AMV pattern shown in Fig. 1b) are imposed in the North Atlantic region, by restoring the model SST to the observed AMV anomalies plus the model's own SST climatology from $0^{\circ}$ to $73^{\circ} \mathrm{N}$. Outside of the restoring region, the models were let free, allowing a response of the full coupled climate system. Two additional sets of experiments similar to the Full_AMV experiments, but with the model North Atlantic SSTs restored to the observed AMV only in the North Atlantic subpolar gyre (SPG_AMV) or in the Tropical North Atlantic (Trop_AMV), were performed with CESM1 and CM2.1. For all experiments, we performed large ensemble simulations with 100 members for CM2.1, 30 members for CESM1, and 50 members for FLOR in order to robustly estimate the AMV climate impacts and the associated signal-to-noise ratio. In order to capture the potential response and adjustment of other oceanic basins to the AMV anomalies, all the simulations were integrated for 10 years with fixed external forcing conditions. In this article, we focus on the boreal winter ${ }^{1}$ climate response to AMV forcing and we discuss only the ensemble mean differences between the AMV+ and AMVsimulations. Further details regarding the experimental set-up and their results can be found in Ruprich-Robert et al. (2017) and Castruccio et al. (in revision).

\section{Results \\ a) Global impacts of the AMV}

During DJFM, restoring the three models to the observed AMV yields, as expected, a North Atlantic warming (Fig. $2 \mathrm{a}-\mathrm{c})$. The temperature pattern of the simulated anomalies shows some differences with the observed one of Fig. $1 \mathrm{~b}$. Specifically, the relative strength of the SPG anomalies compared to the tropical anomalies is much less than the observed one. This comes from our choice to keep a time and space invariant restoring timescale for the SST. By so doing, the extratropical North Atlantic SSTs are weakened due to the SPG deep mixed layers, which dilutes the imposed SST anomaly over a deeper oceanic column.

Regardless of this weakness, we find that outside of the North Atlantic, the three models simulate remarkably similar global teleconnections. We note a slight warming of the Indian Ocean and a negative phase of the IPO over the Pacific. The latter has negative SST anomalies in the Tropical Pacific that extend toward the higher latitudes in both Hemispheres along the eastern ocean boundary, in a horseshoe-like pattern, surrounding positive SST anomalies in the West. The three models show a warming of $\sim 0.3^{\circ} \mathrm{C}$ over Mexico and the Eastern part of US, a warming over East Brazil as well as over South Asia and the Mediterranean area. The models also agree on the simulated warming over Siberia and on the cooling of the northwestern part of North America. In response to $\mathrm{AMV}+$ forcing, CESM1 simulates a significant warming of the Arctic that is only found over the northeastern rim of Siberia in CM2.1 and FLOR. The models also disagree on the temperature response over Northern Europe: CM2.1 simulates a warming there whereas CESM1 and FLOR tend to simulate a cooling.

We find that AMV leads to significant changes in the atmospheric winter circulation as illustrated by precipitation and geopotential height at $500 \mathrm{hPa}$ (Z500) anomalies (Figs. 2d-f and Fig. 3b) ${ }^{2}$. There is a northward shift and a reinforcement of the Intertropical Convergence Zone all over the tropical belt as well as a southwestward shift of the South Pacific Convergence Zone. The precipitation response over the Tropical Pacific is coherent with a La Niña-like temperature pattern seen in Figs. 2a-b. We further analyzed the amplitude of the ENSO response ${ }^{3}$ and found that in all models the occurrence of La Niña events roughly doubles between the Full_AMV-and the Full_AMV+ experiments.

Over the extratropical North Pacific, the AMV leads to a weakening of the Aleutian Low (Fig. 3b) associated with an east-west dipole in the precipitation anomalies over the

\footnotetext{
${ }^{1}$ Defined as the December to March seasonal mean. ${ }^{2}$ In view of concision, only $\mathrm{Z} 500$ response from CESM1 is shown here, but we specify in the following when this response is different among the models.

${ }^{3}$ To do so, we defined an ENSO index based on the first EOF of the upper 200 $\mathrm{m}$ oceanic heat content computed over the tropical Pacific $\left(30^{\circ} \mathrm{S}-30^{\circ} \mathrm{N}\right)$.
} 

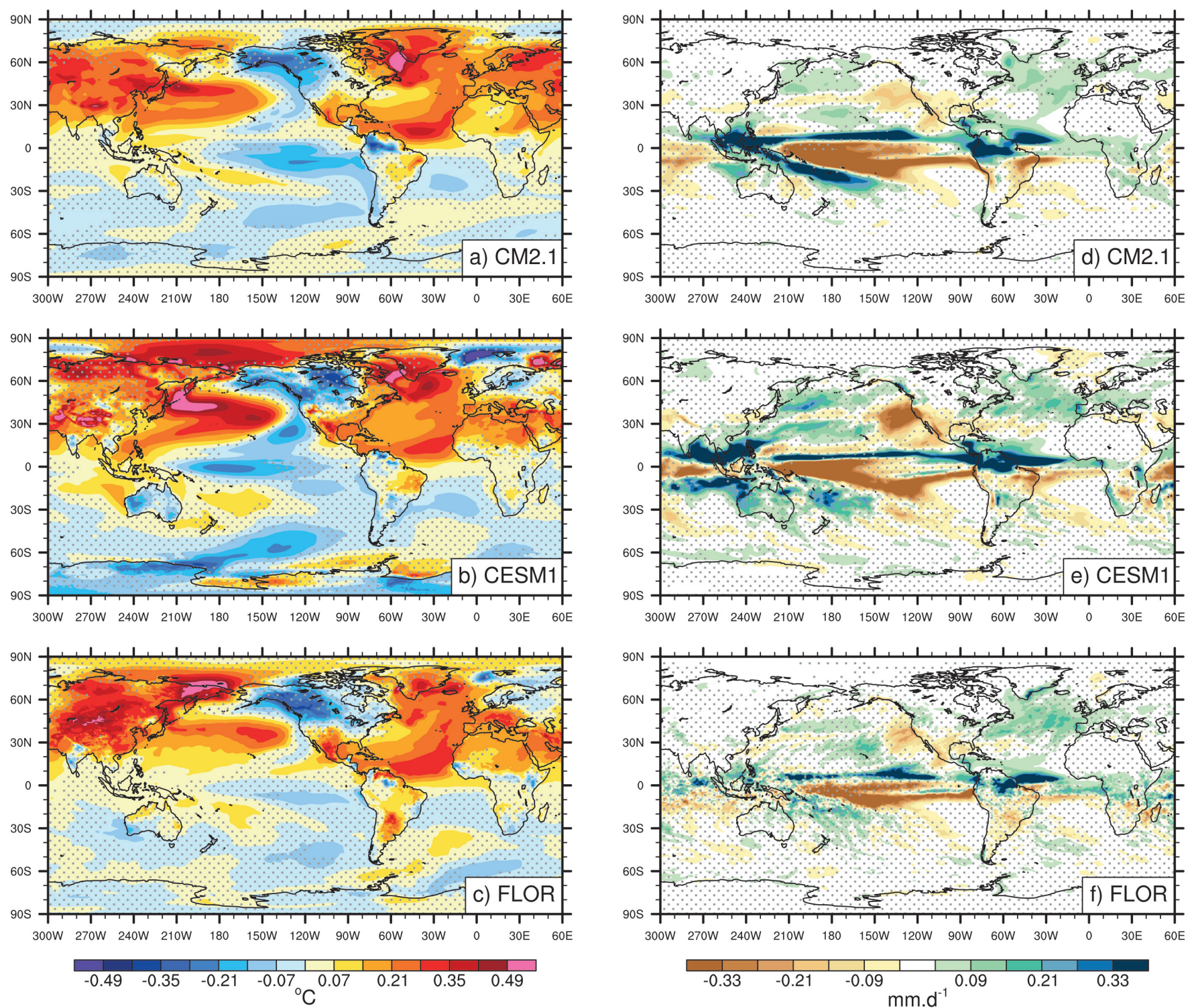

Figure 2: Differences between the 10-year average of the Full_AMV+ and the Full_AMV- ensemble simulations for December to March (DJFM) of ( $a, b, c)$ 2-meter air temperature and ( $d, e, f)$ precipitation. Results are shown from top to bottom for CM2.1, CESM1, and FLOR. Stippling indicates regions that are below the 95\% confidence level of statistical significance according to a twosided t-test. Note that the contours intervals of T2 in a, b, and c have been multiplied by 1.75 compared to Figure $\mathbf{1 b}$.

North Pacific and decrease of precipitation over the west coast of US and Mexico (Figs. 2d-f). The Z500 anomalies are reminiscent of the negative phase of the Pacific North America pattern (PNA) (Barnston and Livezey, 1987), with positive Z500 anomalies centered over the Aleutian Low and Mexico and negative anomalies over Canada and south of Hawaii. The latter center of action is more visible when looking at streamfunction anomalies at $200 \mathrm{hPa}$ (hereafter SF200; Fig. 3b).

The North Pacific SST response is also consistent with the Aleutian Low weakening as discussed by Zhang and Delworth (2015). In their study, they linked a northward shift of the westerlies to a northward shift of the oceanic gyre circulation through a Sverdrup balance and to the propagation of oceanic Rossby waves from the central Pacific to the western coast, explaining the warmer SST off Japan. Over the northeastern side of the North Pacific, the SST cooling is driven by an anomalous advection of cool air from the Arctic. Furthermore, this whole North Pacific response is reminiscent of that documented in the water hosing experiments of Zhang and Delworth (2005), Dong and Sutton (2007) and Okumura et al. (2009), although the impacts are weaker in our experiments as expected from the weaker imposed forcing.

While the North Pacific response is significant and robust among the three models, the North Atlantic - Europe (NAE) response is notably weaker. All models simulate an increase of precipitation over Southern Europe, but these 

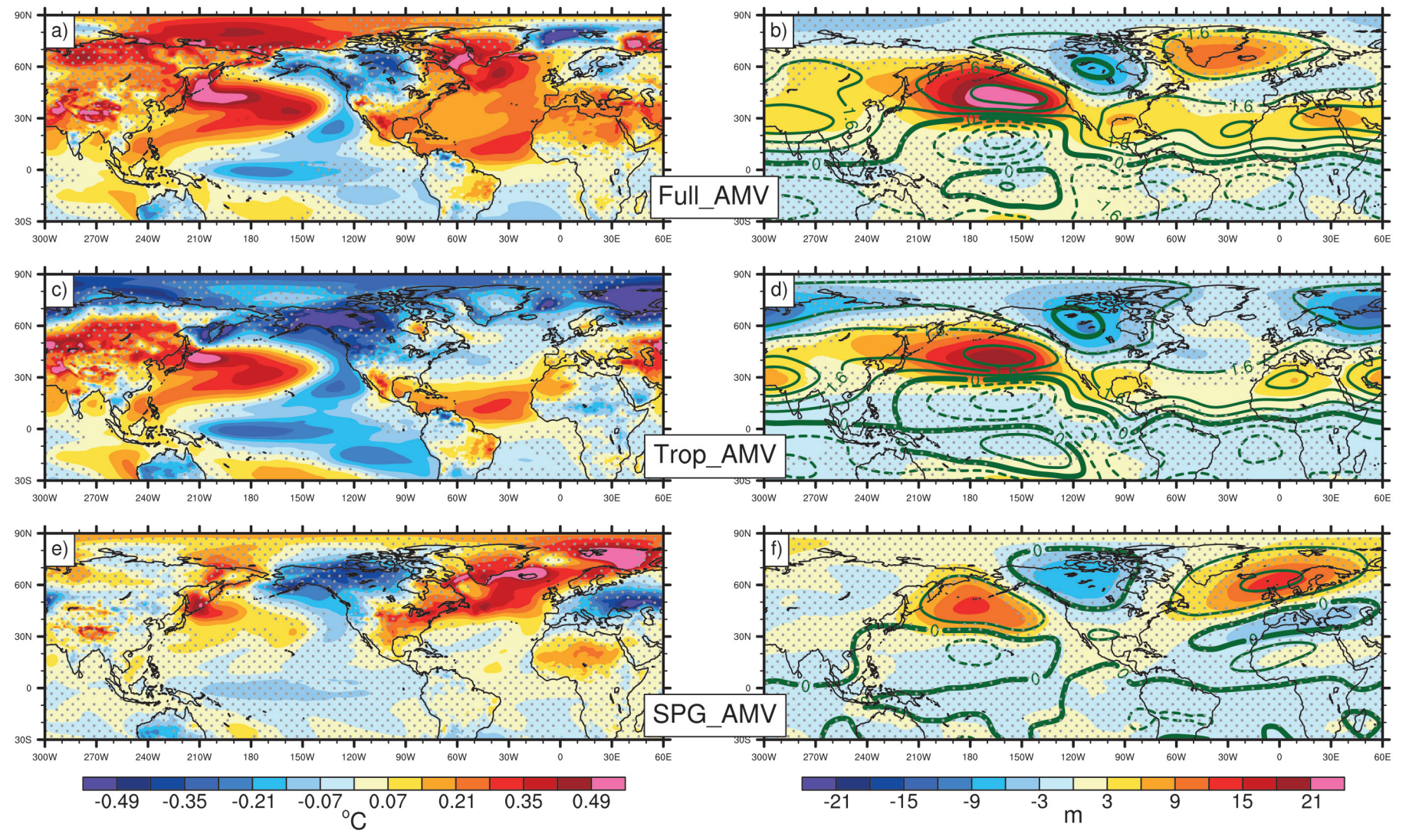

Figure 3: Difference between the 10-year average of the positive and the negative phases of (a, b) Full_AMV, (c, d) Trop_AMV, (e, f) SPG_AMV for CESM1 in DJFM. (left) 2-meter air temperature (T2m) and (right) geopotential height at 500 hPa (Z500, color) and streamfunction of the wind at $200 \mathrm{hPa}$ (SF200, contours at intervals of $0.8 \times 10^{6} \mathrm{~m}^{2} \mathrm{~s}^{-1}$ ). Stippling indicates regions that are below the 95\% confidence level of statistical significance. Figure adapted from Ruprich-Robert et al. (2017). (C)American Meteorological Society. Used with permission.

anomalies are only significant in CESM1. In CESM1 and FLOR, these precipitation anomalies are associated with a weak anomalous north-south Z500 dipole that projects on the NAO in its negative phase (hereafter NAO-). The geopotential anomalies in CM2.1 do not project strongly onto the $\mathrm{NAO}$, even though positive anomalies are present over Iceland. For CM2.1 this diagnostic suggests that the NAE atmospheric response might project onto a mix of both an NAO- and a negative phase of the East Atlantic Pattern ${ }^{4}$ (not shown). We further quantified the signalto-noise ratio of the climate response to AMV and, for all models we found that the NAE atmospheric response accounts for less than $10 \%$ of the decadal variance. The discrepancy between the models and the weak atmospheric response over the NAE region suggest that the AMV does not strongly impact the atmosphere over there. We acknowledge however that our experimental protocol may lead to an underestimation of the extratropical AMV forcing and hence potentially to an underestimation of the atmospheric response over the NAE region. Indeed, as discussed above, our choice to keep a time and spatially-invariant restoring timescale does not allow to strongly constrain the SST over a region with deep oceanic mixed layer such as the SPG.

\section{b) Tropical vs Extratropical SST contribution to the AMV climate impacts}

We investigated the respective contribution of the tropical and extratropical parts of the AMV to the climate impacts described in the previous section by performing two additional sets of experiments in which only the subpolar (SPG_AMV) or the tropical (Trop_AMV) parts of the AMV pattern were imposed. Only the results from the CESM1 experiments are shown here, but these experiments were also performed with CM2.1 and we discuss the results from both models. We find that the Pacific IPO-like and PNA-like responses are primarily driven by the tropical part of the AMV (Figs. 3c,d). This result corroborates the studies of Kucharski et al. (2015) and McGregor et al. (2014) who suggested that the tropical Pacific cooling observed during the last decades was forced by the tropical Atlantic warming through a modification of the Walker Circulation. In line with Sutton and Hodson (2005), we find that the AMV impacts over the Americas are mainly explained by the tropical part of the AMV but that they are reinforced by the subpolar part of the phenomenon (Figs. 3a,c,e).

${ }^{4}$ This mode is defined in observations as the second mode of variability of the atmosphere over the NAE region (e.g., Barnston and Livezey 1987). 
The models show marginal impacts over North Africa and Europe in terms of $\mathrm{T} 2 \mathrm{~m}$ anomalies in response to the tropical AMV anomalies only, whereas a warming of North Africa and a cooling of Europe is simulated in response to the SPG anomalies. This cooling is consistent with the Z500 dipole anomaly seen over the NAE region, which tends to decrease the atmospheric flow from the relatively warm ocean to the relatively cool European continent in winter. Further, the $\mathrm{Z} 500$ dipole response in the SPG_AMV experiment is shifted eastward compared with the NAO response seen in the Full_AMV experiment (Fig. 3b). This suggests that the subpolar part of the AMV is the primarily driver of the NAE atmospheric response but that both the tropical and the extratropical parts of the AMV contribute to the overall NAE atmospheric response.

The SPG_AMV experiment generates a strikingly larger global atmospheric response in CESM1 than in CM2.1. For the former, the subpolar gyre part of the AMV leads to impacts in T2m and Z500 over the North Pacific region that are weaker but similar in pattern to those driven by the tropical part of the AMV. This is consistent with the weak but significant warming simulated in the tropical North Atlantic in the CESM1 SPG_AMV experiment. This also suggests that part of the tropical signature of the AMV is forced by the subpolar part of the AMV as suggested by Dunstone et al. (2011) and Smirnov and Vimont (2012) but that this mechanism is model-dependent.

\section{Summary and discussion}

We investigated the climate impacts associated with the internal component of the observed Atlantic Multidecadal Variability (AMV) using the GFDL-CM2.1, the NCARCESM1, and the GFDL-FLOR coupled models, by restoring their North Atlantic SSTs to the observed anomalies. This coupled approach allowed us to determine the full climate response to the imposed North Atlantic anomalies.

Over the North Atlantic European (NAE) region, we show that, despite the large-scale warming of the Northern Hemisphere continents simulated in all models during the boreal winter (DJFM), the models disagree on the Northern Europe temperature response. They disagree also on the NAE atmospheric circulation response, which projects on the negative phase of the North Atlantic Oscillation (NAO) for CESM1 and FLOR. The disagreement between the models and the weak signalto-noise ratio of the NAE atmospheric response reveal strong uncertainties on the role played by the AMV in the decadal variations of the NAO observed during the last century. They also suggest the need to repeat such coordinated experiments with other models.

For the three models, we find that the AMV warming drives a change in the Walker Circulation that drives precipitation anomalies over the whole tropical belt. The AMV warming leads also to reduced rainfall over the western part of the US and Mexico and to a weak increase of rainfall over Europe. The Walker Circulation response is associated with broad Pacific anomalies that project onto the Interdecadal Pacific Oscillation (IPO) in its negative phase. In the three models the northern part of the IPOlike SST response is tightly linked to a negative phase of the Pacific North American teleconnection pattern (PNA). We find that both the IPO and PNA-like responses are mainly driven by the Tropical part of the AMV.

Our results stress the importance played by the North Atlantic Ocean variability associated with the AMV in driving decadal changes on a global scale, especially in the Pacific. They also indicate that the AMV has played an important role in global climate variability observed during the last century. In the present study, we specifically focus on the climate impacts associated with an estimate of the internal component of the observed AMV, which has been shown as predictable to some extent on multi-year to decadal timescale (e.g., Robson et al., 2012; Yeager et al., 2012; Msadek et al., 2014). Our results are therefore encouraging for the prospect of getting skillful decadal predictions over regions outside of the North Atlantic through the impacts of AMV. The teleconnections we highlight between the Atlantic and the Pacific are also consistent with the studies of Chikamoto et al. (2012, 2015), who showed that phase shifts of the IPO as those observed in the late 1990's might be predicted few years in advance if the sign and amplitude of the AMV are predicted.

The general impacts and mechanisms described in the present study are based on three climate models that show quite similar results despite their different atmospheric resolution. This gives confidence in the robustness of our conclusions regarding AMV impacts. However, conducting such experiments within a multimodel framework, using other coupled climate models, will be highly beneficial to strengthen our conclusions. This will be done as part of the CMIP6 Decadal Climate Prediction Project (DCPP), which calls for coordinated experiments following a protocol similar to the one proposed in this study (Boer et al., 2016).

\section{Acknowledgment}

The analysis and plots of this paper were performed with the NCAR Command Language (version 6.2.0, 2014), Boulder, Colorado (UCAR/NCAR/CISL/VETS, http:// dx.doi.org/10.5065/D6WD3XH5). NCAR is sponsored by the National Science Foundation (NSF). The CESM is supported by the NSF and the US Department of Energy. This work is supported by the NSF under the Collaborative Research EaSM2 grant OCE-1243015 to NCAR and by the NOAA Climate Program Office under the Climate Variability and Predictability Program grant NA130AR4310138 to NCAR and GFDL. 


\section{References}

Barnston, A. G., and R. E. Livezey, 1987: Classification, seasonality and persistence oflow-frequency atmospheric circulation patterns. Mon. Weather Rev., 115, 1083-1126, doi:10.1175/1520-0493(1987)115<1083:CSAPOL>2.0. CO;2.

Boer, G. J., and Coauthors, 2016: The Decadal Climate Prediction Project. Geosci. Model Dev. Discuss., 0, 1-32, doi:10.5194/gmd-2016-78. http://www.geosci-modeldev-discuss.net/gmd-2016-78/.

Castruccio, F., Y. Ruprich-Robert, S. Yeager, G. Danabasoglu, R. Msadek, T. Deloworth, 2017: Modulation of Arctic Sea Ice Loss by Atmospheric Teleconnections from Atlantic Multi-decadal Variability. Geophys. Res. Lett., in revision.

Chikamoto, Y., M. Kimoto, M. Watanabe, M. Ishii, and T. Mochizuki, 2012: Relationship between the Pacific and Atlantic stepwise climate change during the 1990s. Geophys. Res. Lett., 39, 2-7, doi:10.1029/2012GL053901.

Chikamoto, Y., and Coauthors, 2015: Skilful multi-year predictions of tropical trans-basin climate variability. Nat. Commun., 6, 6869, doi:10.1038/ncomms7869. http:// www.nature.com/doifinder/10.1038/ncomms7869.

Chylek, P., M. K. Dubey, G. Lesins, J. Li, and N. Hengartner, 2014: Imprint of the Atlantic multi-decadal oscillation and Pacific decadal oscillation on southwestern US climate: past, present, and future. Clim. Dyn., 43, 119129, doi:10.1007/s00382-013-1933-3. http://link. springer.com/10.1007/s00382-013-1933-3.

Davini, P., J. Von Hardenberg, and S. Corti, 2015: Tropical origin for the impacts of the Atlantic Multidecadal Variability on the Euro-Atlantic climate. Environ. Res. Lett., 10, 094010, doi:10.1088/17489326/10/9/094010. http://stacks.iop. org $/ 1748-9326 / 10 / \mathrm{i}=9 / \mathrm{a}=094010$ ? key=crossref. e13c7c1e10966cb8fd2a872e288a8724.

Delworth, T. L., and Coauthors, 2006: GFDL's CM2 global coupled climate models. Part I: Formulation and simulation characteristics. J. Clim., 19, 643-674, doi:10.1175/JCLI3629.1.

Dong, B., and R. T. Sutton, 2007: Enhancement of ENSO Variability by a Weakened Atlantic Thermohaline Circulation in a Coupled GCM. J. Clim., 20, 4920-4939, doi:10.1175/JCLI4284.1. http://journals.ametsoc.org/ doi/abs/10.1175/JCLI4284.1.

Dunstone, N. J., D. M. Smith, and R. Eade, 2011: Multi-year predictability of the tropical Atlantic atmosphere driven by the high latitude North Atlantic Ocean. Geophys. Res. Lett., 38, n/a - n/a, doi:10.1029/2011GL047949. http:// doi.wiley.com/10.1029/2011GL047949(Accessed
December 16, 2013).

Enfield, D. B., A. M. Mestas-Nuñez, and P. J. Trimble, 2001: The Atlantic Multidecadal Oscillation and its relation to rainfall and river flows in the continental U.S. Geophys. Res. Lett., 28, 2077.

Gastineau, G., and C. Frankignoul, 2015: Influence of the North Atlantic SST Variability on the Atmospheric Circulation during the Twentieth Century. J. Clim., 26, 2969-2972, doi:10.1029/1999GL900613.

Hakkinen, S., P. B. Rhines, and D. L. Worthen, 2011: Atmospheric Blocking and Atlantic Multidecadal Ocean Variability. Science (80-. )., 334, 655-659, doi:10.1126/ science.1205683. http://www.sciencemag.org/cgi/ doi/10.1126/science.1205683.

Hermanson, L., R. Eade, N. H. Robinson, N. J. Dunstone, M. B. Andrews, J. R. Knight, A. A. Scaife, and D. M. Smith, 2014: Forecast cooling of the Atlantic subpolar gyre and associated impacts. Geophys. Res. Lett., 41, 51675174, doi:10.1002/2014GL060420. http://doi.wiley. com/10.1002/2014GL060420.

Kay, J. E., and Coauthors, 2015: The Community Earth System Model (CESM) Large Ensemble Project: A Community Resource for Studying Climate Change in the Presence of Internal Climate Variability. Bull. Am. Meteorol. Soc., 96, 1333-1349, doi:10.1175/ BAMS-D-13-00255.1. http://journals.ametsoc.org/doi/ abs/10.1175/BAMS-D-13-00255.1.

Kucharski, F., F. S. Syed, A. Burhan, I. Farah, and A. Gohar, 2015: Tropical Atlantic influence on Pacific variability and mean state in the twentieth century in observations and CMIP5. Clim. Dyn., 44, 881-896, doi:10.1007/ s00382-014-2228-z. http://link.springer.com/10.1007/ s00382-014-2228-z.

Li, X., S.-P. Xie, S. T. Gille, and C. Yoo, 2015: Atlantic-induced pan-tropical climate change over the past three decades. Nat. Clim. Chang., 1-13, doi:10.1038/nclimate 2840. http: / / www.nature.com/doifinder / 10.1038 / nclimate2840.

Mahajan, S., R. Zhang, and T. L. Delworth, 2011: Impact of the Atlantic Meridional Overturning Circulation (AMOC) on Arctic Surface Air Temperature and Sea Ice Variability. J. Clim., 24, 6573-6581, doi:10.1175/2011JCLI4002.1. http://journals.ametsoc. org/doi/abs/10.1175/2011JCLI4002.1.

McCabe, G. J., M. a Palecki, and J. L. Betancourt, 2004: Pacific and Atlantic Ocean influences on multidecadal drought frequency in the United States. Proc. Natl. Acad. Sci. U. S. A., 101, 4136-4141, doi:10.1073/pnas.0306738101. 
McGregor, S., A. Timmermann, M. F. Stuecker, M. H. England, M. Merrifield, F.-F. Jin, and Y. Chikamoto, 2014: Recent Walker circulation strengthening and Pacific cooling amplified by Atlantic warming. Nat. Clim. Chang., 4, 888-892, doi:10.1038/nclimate2330. http:// www.nature.com/nclimate/journal/v4/n10/full/ nclimate2330.html?WT.ec_id=NCLIMATE-201410.

Mohino, E., S. Janicot, and J. Bader, 2011: Sahel rainfall and decadal to multi-decadal sea surface temperature variability. Clim. Dyn., 37, 419-440, doi:10.1007/s00382010-0867-2. http://link.springer.com/10.1007/s00382010-0867-2.

Msadek, R., and Coauthors, 2014: Predicting a Decadal Shift in North Atlantic Climate Variability Using the GFDL Forecast System. J. Clim., 140707141053007, doi:10.1175/JCLI-D-13-00476.1.http: / /journals. ametsoc.org/doi/abs/10.1175/JCLI-D-13-00476.1.

Okumura, Y. M., C. Deser, A. Hu, A. Timmermann, and S.-P. Xie, 2009: North Pacific Climate Response to Freshwater Forcing in the Subarctic North Atlantic: Oceanic and Atmospheric Pathways. J. Clim., 22, 1424-1445, doi:10.1175/2008JCLI2511.1. http://journals.ametsoc. org/doi/abs/10.1175/2008JCLI2511.1 (Accessed December 16, 2013).

Omrani, N. E., N. S. Keenlyside, J. Bader, and E. Manzini, 2014: Stratosphere key for wintertime atmospheric response to warm Atlantic decadal conditions. Clim. Dyn., 42, 649-663, doi:10.1007/s00382-013-1860-3.

Ruprich-Robert, Y., R. Msadek, F. Castruccio, S. Yeager, T. Delworth, and G. Danabasoglu, 2017: Assessing the Climate Impacts of the Observed Atlantic Multidecadal Variability Using the GFDL CM2.1 and NCAR CESM1 Global Coupled Models. J. Clim., 30, 2785-2810, doi:10.1175/JCLI-D-16-0127.1. http://journals.ametsoc. org/doi/10.1175/JCLI-D-16-0127.1.

Schubert, S., and Coauthors, 2009: A US CLIVAR Project to Assess and Compare the Responses of Global Climate Models to Drought-Related SST Forcing Patterns: Overview and Results. J. Clim., 22, 52515272, doi:10.1175/2009jcli3060.1. < Go to ISI >:// WOS:000270423300018\nhttp://journals.ametsoc.org/ doi/pdf/10.1175/2009JCLI3060.1.

Smirnov, D., and D. J. Vimont, 2012: Extratropical Forcing of Tropical Atlantic Variability during Boreal Summer and Fall. J. Clim., 25, 2056-2076, doi:10.1175/ JCLI-D-11-00104.1. http://journals.ametsoc.org/doi/ abs/10.1175/JCLI-D-11-00104.1.

Sutton, R. T., and D. L. R. Hodson, 2005: North Atlantic forcing of North American and European summer climate.
Science (80-. )., 309, 115-118. papers2://publication/ doi/10.1126/science.1109496.

Sutton, R. T., and D. L. R. Hodson, 2007: Climate Response to Basin-Scale Warming and Cooling of the North Atlantic Ocean. J. Clim., 20, 891-907, doi:10.1175/JCLI4038.1. http://journals.ametsoc.org/doi/abs/10.1175/ JCLI4038.1.

Sutton, R. T., and B. Dong, 2012: Atlantic Ocean influence on a shift in European climate in the 1990s. Nat. Geosci., 5, 788-792, doi:10.1038/ngeo. http://dx.doi.org/10.1038/ ngeo 1595.

Ting, M., Y. Kushnir, R. Seager, and C. Li, 2009: Forced and Internal Twentieth-Century SST Trends in the North Atlantic*. J. Clim., 22, 1469-1481, doi:10.1175/2008JCLI2561.1. http://journals.ametsoc. org/doi/abs / 10.1175/2008JCLI2561.1(Accessed December 16, 2013).

Vecchi, G. A., and Coauthors, 2014: On the Seasonal Forecasting of Regional Tropical Cyclone Activity. J. Clim., 27, 7994-8016, doi:10.1175/JCLI-D-14-00158.1. http://journals.ametsoc.org/doi/abs/10.1175/ JCLI-D-14-00158.1.

Vimont, D. J., and J. P. Kossin, 2007: The Atlantic Meridional Mode and hurricane activity. Geophys. Res. Lett., 34, L07709, doi:10.1029/2007GL029683. http://doi.wiley. com/10.1029/2007GL029683 (Accessed December 16, 2013).

Wittenberg, A. T., A. Rosati, N. C. Lau, and J. J. Ploshay, 2006: GFDL's CM2 global coupled climate models. Part III: Tropical Pacific climate and ENSO. J. Clim., 19, 698722, doi:10.1175/JCLI3631.1.

Yeager, S., A. Karspeck, G. Danabasoglu, J. Tribbia, and H. Teng, 2012: A Decadal Prediction Case Study: Late Twentieth-Century North Atlantic Ocean Heat Content. J. Clim., 25, 5173-5189, doi:10.1175/JCLI-D-11-00595.1. http://journals.ametsoc.org/doi/abs /10.1175/ JCLI-D-11-00595.1 (Accessed December 12, 2013).

Zhang, L., and T. L. Delworth, 2015: Analysis of the Characteristics and Mechanisms of the Pacific Decadal Oscillation in a Suite of Coupled Models from the Geophysical Fluid Dynamics Laboratory. J. Clim., 28, 76787701, doi:10.1175/JCLI-D-14-00647.1. http://journals. ametsoc.org/doi/abs/10.1175/JCLI-D-14-00647.1.

Zhang, R., and T. L. Delworth, 2005: Simulated Tropical Response to a Substantial Weakening of the Atlantic Thermohaline Circulation. J. Clim., 18, 1853-1860. 